\title{
Advance care planning for paediatric patients
}

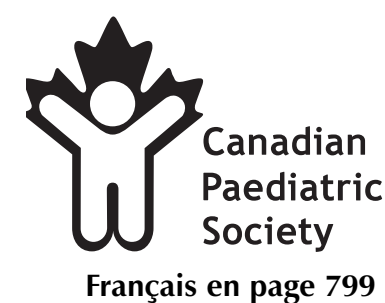

\begin{abstract}
Medical and technological advances have increased survival rates and enhanced the quality of life for infants, children and youths with chronic life-threatening conditions. Advance care planning includes the process of discussing life-sustaining treatments and establishing long-term care goals. Paediatric health care practitioners have an ethical obligation to educate themselves about this aspect of medical care. The present statement aims to assist health care practitioners to discuss advance care planning for paediatric patients in varied settings. Advance care planning requires effective communication to clarify the goals of care and establish agreement on what treatments may or may not be appropriate to achieve these goals, including resuscitative and palliative measures.
\end{abstract}

Key Words: Advance directives; Consent; Palliative care

\section{BACKGROUND}

Medical and technological advances have resulted in higher survival rates in a cohort of children with complex health conditions, many of whom would not have survived previously $(1,2)$. Although robust, longitudinal population-based epidemiological studies of childhood illnesses and disabilities are lacking, we know that rates are increasing $(2,3)$. These children often require multiple interventions to maintain their health including surgical procedures, hospitalizations and home technological supports. With the complexity of these conditions, parents frequently face difficult decisions about which interventions should be performed on their child because some are accompanied by significant burdens. The potential for burden mandates health care providers to carefully counsel families and legal guardians, acknowledging the delicate balance between promoting survival and compromising quality of life. Our aim as paediatric health care providers should be "to add life to the child's years, not simply years to the child's life" (4).

There is a dearth of information regarding advance care planning in the paediatric population compared with the adult population, in which there is much clinical experience and research. A number of factors contribute to this gap. The emphasis on beneficence rather than patient autonomy in parental substitute decision-making leads to a prima facie bias toward curative rather than palliative options. This bias is consistent with parental obligation to protect children and societal predisposition in favour of life.
Parents, health care providers and society, in general, have the expectation that children will outlive their parents. The overriding instinct to protect children from harm may lead to avoidance of difficult topics, even to the extent that some children, despite having adequate capacity to understand and cope with their condition, are excluded from discussions about the gravity of their illness.

What is advance care planning? It is an extension of usual discussions about the treatment plan, which generally deal with curative measures and focus more on what will be provided rather than what will not. It broadly encompasses both short-term and long-term health care goals and treatments. It may include the drafting of formal advance directives, which specify what treatments will or will not be provided to the patient. The benefits of advance care planning are both procedural, in that two-way communication is improved, as well as substantive, in that the actual details of the plan of care are clarified. When advance care planning is executed well, we ensure that shared goals of care, be they curative or palliative, are aligned with the planned course of treatment.

\section{STATEMENT OF PROBLEM}

\section{Current status}

Advance care planning in paediatrics is largely limited to intensive care settings and specific disease populations. The stimulus for discussion is often the anticipation of impending death, where the expected outcomes of discussion include 'do not resuscitate' (DNR) orders and palliative care consultations. There may be an abrupt transition from a curative to a palliative focus of care, with the intent to avoid prolongation of the time to death and to limit nonbeneficial or even harmful treatments.

DNR orders became widely used after 1976, with the recognition that cardiopulmonary resuscitation (CPR) may be inappropriate for certain patients and with the acknowledgement of the patient's right to consent to or decline medical treatment (5). Today, DNR orders may stand alone or may be incorporated into a larger plan to limit treatment. Problems arise, however, when the DNR order is perceived to encompass limitation of additional therapies beyond resuscitation, resulting in confusion among members of the health care team about which interventions will or will not be provided (6). One Alberta study (7) demonstrated that 46.9\% of DNR policies contained an array of directives regarding 
interventions other than CPR, including antibiotics and intravenous fluids. Some health care institutions have replaced the term DNR with 'do not attempt resuscitation', 'no CPR' or 'allow natural death'. Practitioners should be aware of the DNR policies and terminology used at their local institutions. Whether any change in nomenclature can eliminate the confusion associated with DNR orders is unknown. Nevertheless, these problems highlight the need for clear communication when discussing advance care planning.

Parents may be overly optimistic compared with physicians about their child's prognosis (8); the converse, however, may also occur. Health care professionals may underestimate parental understanding and receptiveness to discussions about forgoing life-sustaining interventions. A retrospective survey (9) of parents whose children died in paediatric intensive care units showed that although the discussion was initiated by physicians $90 \%$ of the time, almost one-half of those parents reported that they had considered withdrawal of treatment before the option was raised by the staff. In the critical care environment (paediatric and neonatal intensive care), these discussions are initiated when it is believed that the patient is likely to die; the health care team is motivated by the desire to ensure the family agrees that what the team considers to be 'futile' treatments will not be provided.

Although the possibility of premature death is widely known for many conditions (eg, paediatric cancers, cystic fibrosis and Duchenne muscular dystrophy), preferences regarding refusal of treatment may not be solicited if members of the health care team assume that the patient and their family are in favour of active treatment. An international survey (10) showed that $45 \%$ of paediatric oncologists do not initiate this discussion. These discussions may occur even less commonly for paediatric patients with chronic conditions, in whom the timing of death cannot be easily predicted (eg, severe cerebral palsy, neurodegenerative disorders, palliative cyanotic congenital heart disease and short gut syndrome). For adults, noncancer diagnoses represent, on average, only $5 \%$ of palliative care referrals; communication about death and dying appears to be less consistent for patients suffering from deteriorating chronic illnesses (11). Because parents and children may not be overtly aware of the potential for dying until discussion is initiated, the health care practitioner has an obligation to share valuable information and provide the opportunity for reflection.

\section{ADVANCE CARE PLANNING FOR CHRONIC LIFE-THREATENING CONDITIONS - A NEW STANDARD OF CARE}

Why should advance care planning be part of the standard of care for paediatric patients? Health care providers should be aware of literature that suggests palliative care is appropriate not only when children are dying, but at any point following diagnosis of a life-limiting condition. One analogy that has been presented is that of a 'dimmer switch' instead of an 'onoff switch' model of palliative care, such that palliative measures are introduced simultaneously with potentially curative treatments. To discuss advance care planning only in acutely life-threatening situations may be discriminatory; opportunity would be limited to patients with conditions that result in episodes of critical illness before the preterminal phase.

An approach that integrates the principles of palliative care can be beneficial when implemented early and throughout the course of the child's illness. The principles embodied by contemporary palliative medicine include the relief of suffering and a focus on the quality of living and dying, rather than being limited to end-of-life care. Although palliative care services are not always formally accessed, they can complement other therapies during the active treatment phase. For those patients who die, palliative care continues as bereavement support (12).

Discussing advance care planning early in the course of disease avoids equating options, such as DNR orders and palliative care, with 'giving up' on the patient. Decisions to forgo life-sustaining treatment are distinct from active euthanasia, in which the sole intended outcome is to directly cause death. The primary intent underlying decisions to forgo selected life-sustaining treatments should not be to hasten the death of the infant, child or youth, but rather to optimize the quality of life. Health care practitioners should be aware of their own potential feelings of failure when a child has a terminal illness, which may contribute to reluctance to initiate discussion. It may be helpful during discussions to supplant the perception that one is 'giving up' on the child with the concept of accepting (or 'giving in' to) the reality of the disease process. Altering the care plan to meet the child's individual needs should improve the quality of care, and may even produce surprising satisfaction or even relief among caregivers.

Most parents want physicians to discuss advance care planning options with them and help them make decisions (13). Effective communication skills are required, including familiarity with developmentally appropriate language, if the child is included in the discussions. Rather than asking parents whether they want 'everything' to be provided for their child, it is better to be clear and decide on individual interventions that are feasible within the context of the child's illness. It is important to be sensitive to emotions that may surface including fear, guilt, anger, denial and surprise. In anticipation of these reactions, it may help to be explicit about the shift in focus from cure and survival to comfort and well being. The benefits for parents include knowing that they have assured the best care for their child, including preserving quality of life and avoiding unnecessary pain or suffering (14).

Who should initiate discussion about advance care planning? It may be a trusted health care provider (eg, oncologist) with primary responsibility for the most significant illness at the time. Advance care planning, however, should eventually involve other members of the team to address physical, psychological and spiritual needs of the child and their family (1). Consultation with other specialists involved with the child's care may be helpful. When dealing with families from a nondominant culture, input from a respected spiritual leader or use of language interpreters can be invaluable. Multiple discussions are often required. Even 
in the paediatric intensive care setting, in which decisionmaking often occurs on a compressed timeline, one Canadian study (15) found that two or more meetings were required to achieve consensus in $46 \%$ of cases involving decisions to forgo life-sustaining therapy. Effective communication includes being open and available for feedback, having ongoing discussions and re-evaluating treatment goals.

\section{ETHICAL ISSUES IN ADVANCE CARE PLANNING}

The ethical principles that underlie advance care planning are the same as in other health care encounters - respect for autonomy, beneficence and nonmaleficence. Any treatment considered should be in respect to the anticipated benefits and burdens, and should be undertaken only when the benefits proportionately outweigh the burdens (16). Herein lies the challenge - to predict benefits and burdens within the complex contexts of uncertainty and varying values. Potential outcomes must be evaluated based on facts and values, which may be very subjective. As much as we use the phrase 'family-centred care', we can only fulfill this ideal by providing a comprehensive standard of care, which includes advance care planning.

Paediatric patients fall into one of three categories in terms of decision-making capacity - incapable of consent, developing capacity for consent and fully capable of consent. The last category defines the mature minor, who is legally not an adult according to chronological age criteria, yet has the cognitive ability to consider treatment choices and alternatives and weigh the consequences. For minors who are either fully competent or have evolving capacity, the principle of respect for autonomy demands that we inform them, either so they can make their own health care decisions, or at least be aware of what is happening with their health. A recent Scandinavian study (17) found that one-fourth of parents regretted not talking about death with their child who was dying of cancer, suggesting that one of our responsibilities is to help parents address this issue. Providing information is consistent with the duty to be honest with our patients. We respect their dignity by only administering treatments that they have freely chosen and desire.

A family-centred approach, however, may be a doubleedged sword if the patient and family members do not share the same goals. This potential for conflict is greatest in situations in which the minor is in the middle category developing capacity for consent. Parents may consider themselves to know best, to the exclusion of the child or youth, and also expect others to accept their decisions without question. Health care professionals should be aware of differences in how burden is perceived, looking from the perspective of the child in isolation versus being embedded in a family unit. It may be difficult to separate the best interests of the child from those of their caregivers and extended family members. If the patient and family do not appear to be ready to address advance care planning, particularly when death is not imminent, respect for autonomy and parental authority includes the option of allowing them to refuse information and defer decision-making.

\section{BARRIERS TO IMPLEMENTATION OF ADVANCE DIRECTIVES}

Advance care planning may involve drafting of formal advance directives, which include instructional and/or proxy directives. Instructional directives indicate what actions should be taken in the case of anticipated health crises, while proxy directives indicate who should be consulted to decide in the case of patient incapacity. The former is most relevant to the paediatric population because it is very rarely that we do not know who should be the substitute decision-maker; it is legally stipulated (ie, parents or other legal guardians, such as child protection agencies). Nevertheless, for patients to issue legally valid advance directives, they must be competent to do so. Most jurisdictions in Canada do not have legislation granting legal validity to advance directives made by mature minors. The stipulated legal age for advance directives is 16 years in Saskatchewan, Ontario, New Brunswick, Prince Edward Island and Newfoundland (Table 1).

Why is this legislative barrier a problem? It has been stated that end-of-life decisions are more important than most other health care decisions, yet the wishes of competent youths on these matters may not be respected $(18,19)$. The failure to address this barrier disenfranchises these mature minors who should have the right to participate in all aspects of health care decision-making. The case has been made that even youths without chronic health conditions should have the opportunity to express advance directives because they too are at risk for unexpected catastrophic illnesses or accidents, although most healthy adults do not avail themselves of this option (20). The gaps in legislation not only affect mature minors, but also incapable minors and minors who are parents. The legal age for being a substitute decision-maker varies from no age limit (in Ontario and in Prince Edward Island) for the parent of a child to the age of majority in other provinces.

It is becoming more common for DNR directives and other 'advance directives' (eg, letters written by physicians) to be drafted by health care practitioners with the input of parents for their children. There are concerns about the variable acceptance of these advance directives by third parties (eg, schools and emergency medical services). The lack of legal status, because they are drafted by substitute decision-makers and not the patient, puts the parents of these children in potentially thorny situations, in which their wishes may not always be respected. A recent American study (21) found that $80 \%$ of public school districts did not have policies, regulations or protocols for dealing with student DNR directives, and $76 \%$ either would not honour them or were uncertain whether they could. The same may apply in Canada, not only for schools, but also for hospitals, walk-in clinics and emergency medical services. Only recently have paramedics been authorized to withhold resuscitative measures according to written DNR directives or verbal instructions from a valid substitute decision-maker in some jurisdictions. In February 2008, Ontario introduced the DNR confirmation form, a province-wide standard, which is to be completed by a physician or a nurse, and authorizes paramedics or firefighters to honour the DNR wishes of a patient (22). 


\section{TABLE 1}

Summary of Canadian legislation regarding age of consent and advance directives

\begin{tabular}{|c|c|}
\hline Province/Territory & Details of relevant legislation \\
\hline British Columbia & $\begin{array}{l}\text { The age of majority is } 19 \text { years. The Health Care (consent) and Care Facility (admission) Act stipulates that all adults } \\
\text { presumed capable unless proven to be otherwise, substitute decision-maker must be } 19 \text { years of age or more }\end{array}$ \\
\hline & $\begin{array}{l}3 \text { (1) Any person who is at least } 18 \text { years of age and understands the nature and effect of a personal directive may } \\
\text { make a personal directive }\end{array}$ \\
\hline
\end{tabular}

Saskatchewan

The age of majority is 18 years. The Health Care Directives and Substitute Health Care Decision Makers Act stipulates that any person 16 years of age or older who is capable can make a directive. Substitute decision-maker must be an adult (18 years or more)

Manitoba

The Health Care Directives Act stipulates legal age of capacity to be 16 years, presuming that person who made the directive did so when 16 years of age or more. Proxy must be 18 years of age or more

Ontario

Health Care Consent Act has no stipulated statutory age of consent. Substitute decision-maker must be 16 years of age or more unless parent of a child. Must be 16 years of age or more to make advance directive

Quebec

The age of majority in Quebec is 18 years: Civil Code, S.Q. 1991, c.64

14. Consent to care required by the state of health of a minor is given by the person having parental authority or by his tutor. A minor 14 years of age or over, however, may give his consent alone to such care. If his state requires that he remain in a health or social services establishment for over $12 \mathrm{~h}$, the person having parental authority or tutor shall be informed of that fact

16. The authorization of the court is necessary, furthermore, to cause a minor 14 years of age or over to undergo care he refuses, except in the case of emergency if his life is in danger or his integrity threatened, in which case the consent of the person having parental authority or the tutor is sufficient

17. A minor 14 years of age or over may give his consent alone to care not required by the state of his health; however, the consent of the person having parental authority or of the tutor is required if the care entails a serious risk for the health of the minor and may cause him grave and permanent effects

New Brunswick

The age of majority is 19 years. The Medical Consent of Minors Act indicates legal age of consent is 16 years with allowance of mature minors to provide their own consent. No reference to advance directives

Nova Scotia

The Medical Consent Act allows person of the age of majority (19 years) to authorize another individual of the age of majority to provide consent on their behalf when they are no longer competent. No specific reference to advance directives.

Prince Edward Island The Consent to Treatment and Health Care Directives Act indicates all persons presumed capable unless proven otherwise. Substitute decision-maker must be 16 years of age or more unless parent of a child. Must be 16 years of age or more to make advance directive

Newfoundland

and Labrador

The age of majority is 19 years. The Advance Health Care Directives Act stipulates that persons 16 years of age or more presumed competent and younger than 16 years of age is presumed to not be competent, must be competent to make advance directive or appoint substitute decision-maker. Substitute decision-maker must be 19 years of age or more

Yukon

The age of majority is 19 years. The Age of Majority Act, RSY 2002, c.2

Northwest Territories The age of majority is 19 years. The Age of Majority Act, RSNWT 1988, c.A-2

Nunavut

Same as the Northwest Territories.

There may be a role for paediatric health care practitioners to lobby for legislative change that is uniform across Canada so that advance directives expressed by or on behalf of minors become legally valid. In the meantime, capable children and youths can still express their wishes in the hope that adults will take them into account. We should encourage them to make their wishes known widely and consider having them put in writing as 'advance directives', which in practice are being accepted more commonly, despite legislative gaps. We should also advocate for research on advance care planning with paediatric patients with life-threatening conditions, including but not limited to research on decisional capacity, to substantiate our efforts to effect legislative change.

\section{SUMMARY}

Advance care planning is an important element of the health care of all patients with life-limiting illnesses, including the paediatric population. Health care practitioners 
should educate themselves so that they are comfortable with initiating discussion about these issues with children and their families. They should also familiarize themselves with resources available in hospitals and in the community that can be enlisted to provide a holistic, family-centred approach for these children to support advance care plans. Further work needs to be done in terms of policy and legislation to address the current gaps in the status of formal advance directives for minors.

\section{RECOMMENDATIONS}

- Advance care planning is part of the standard of care for paediatricians and other health care practitioners involved in the care of paediatric patients with chronic life-threatening conditions.

- It is our responsibility to initiate these discussions, rather than wait for patients and family members to ask.

- These discussions should occur early and regularly throughout the course of treatment, ideally before crises arise, and as the goals of care are clarified or change over time. Decisions should be reviewed and revised on a regular basis as the medical condition and knowledge of treatment and prognosis evolve.

- Clarification of wishes regarding emergency and lifesustaining therapies including CPR should be obtained and documented (see Appendix for advance care plan checklist) so that these advance directives can be communicated with others, such as home care workers and schools.

- Palliative care is a potential adjunct to the health care of all children with severe chronic conditions with shortened life expectancy. Palliative care options should be integrated into discussions of treatment goals where appropriate.

\section{REFERENCES}

1. Himelstein BP, Hilden JM, Boldt AM, Weissman D. Pediatric palliative care. N Engl J Med 2004;350:1752-62.

2. Judson L. Global childhood chronic illness. Nurs Adm Q 2004;28:60-6.

3. Missiuna C, Smits C, Rosenbaum P, Woodside J, Law M. Incidence and prevalence of childhood disabilities. CanChild Centre for Childhood Disability Research, 2005.

4. American Academy of Pediatrics; Committee on Bioethics and Committee on Hospital Care. Palliative care for children. Pediatrics 2000;106:351-7.

5. Rabkin MT, Gillerman G, Rice NR. Orders not to resuscitate. N Engl J Med 1976;295:364-6.

6. Teres D. Trends from the United States with end of life decisions in the intensive care unit. Intensive Care Med 1993;19:316-22.

7. Wilson DM. Highlighting the role of policy in nursing practice through a comparison of "DNR" policy influences and "no CPR" decision influences. Nurs Outlook 1996;44:272-9.

8. Mack JW, Cook EF, Wolfe J, Grier HE, Cleary PD, Weeks JC. Understanding of prognosis among parents of children with cancer: Parental optimism and the parent-physician interaction. J Clin Oncol 2007;25:1357-62.

9. Meyer EC, Burns JP, Griffith JL, Truog RD. Parental perspectives on end-of-life care in the pediatric intensive care unit. Crit Care Med 2002;30:226-31.
- Paediatric palliative care professionals should be involved early in discussions of treatment goals. Discussions about palliative care should take place well before the paediatric patient is at imminent risk of dying.

- Paediatric health care professionals should advocate for uniform legislation across Canada on advance directives for minors. There is also an opportunity for research on advance care planning with minors with life-threatening conditions.

\section{SUGGESTED MEANS OF IMPLEMENTATION}

- Early initiation of discussion about treatment goals and options regarding advance care planning and ongoing discussion as the medical illness progresses.

- Suggest or arrange family discussions about advance care planning for all mature minors with significant health conditions.

- Engaging in dialogue with different members of the health care team - paediatricians, family physicians, subspecialists, nurses, social workers, spiritual care, teachers and others (including palliative care consultants).

- Advance care plan ('advance directives') checklist.

- Re-evaluation of advance care plans on a regular basis.

ACKNOWLEDGEMENTS: The principal author thanks Dr Gerri Frager (Pediatric Palliative Care Service, Dalhousie University, Halifax, Nova Scotia) and Dr Kathleen Glass (Biomedical Ethics Unit, Departments of Human Genetics and Pediatrics, McGill University, Montreal, Quebec) for their expert advice in their content areas.
10. Hilden JM, Emanuel EJ, Fairclough DL, et al. Attitudes and Practices among pediatric oncologists regarding end-of-life care: Results of the 1998 American Society of Clinical Oncology survey. J Clin Oncol 2001;19:205-12.

11. Kite S, Jones K, Tookman A. Specialist palliative care and patients with noncancer diagnoses: The experience of a service. Palliat Med 1999;13:477-84.

12. Ferris FD, Balfour HM, Bowen K, et al. A model to guide hospice palliative care. Canadian Hospice Palliative Care Association, 2002.

13. Wharton RH, Levine KR, Buka S, Emanuel L. Advance care planning for children with special health care needs: A survey of parental attitudes. Pediatrics 1996;97:682-7.

14. Hammes BJ, Klevan J, Kempf M, Williams MS. Pediatric advance care planning. J Palliat Med 2005;8:766-73.

15. Garros D, Rosychuk RJ, Cox PN. Circumstances surrounding end of life in a pediatric intensive care unit. Pediatrics 2003;112:e371.

16. Canadian Paediatric Society; Bioethics Committee. Treatment decisions regarding infants, children, and adolescents. Paediatr Child Health 2004;9:99-103.

17. Kreicbergs U, Valdimarsdottir U, Onelov E, Henter J, Steineck G. Talking about death with children who have severe malignant disease. N Engl J Med 2004;351:1175-86. 
18. Badzek L, Kanosky S. Mature minors and end-of-life decision making: A new development in their legal right to participation. J Nurs Law 2002;8:23-9.

19. Rosato JL. The ultimate test of autonomy: Should minors have a right to make decisions regarding life-threatening treatment. Rutgers Law Rev 1996;49:1-103.

20. McAliley LG, Hudson-Barr DC, Gunning RS, Rowbottom LA. The use of advance directives with adolescents. Pediatr Nurs 2000;26:471-80.
21. Kimberly MB, Forte AL, Carroll JM, Feudtner C. Pediatric do-not-attempt-resuscitation orders and public schools: A national assessment of policies and laws. Am J Bioeth 2005;5:59-65.

22. Ontario Ministry of Health and Long-Term Care. Do not resuscitate confirmation form: To direct the practice of paramedics and firefighters after February 1, 2008.

<http://www.forms.ssb.gov.on.ca/mbs/ssb/forms/ssbforms.nsf/Attach DocsPublish/014-4519-45 1/\$File/4519-45.pdf $>$ (Version current at October 21, 2008).

\section{APPENDIX}

\section{Preamble}

This checklist is intended to guide health care practitioners to develop an advance care plan that is individualized to the needs of the child. Questions that the patient and/or parents might be asked in preparing an advance care plan include:

- What is your understanding of your/your child's illness? How do you expect it to progress?

- What is the most important thing for you? Management of pain? Relief of breathlessness? Being at home or with family?

- If you/your child would not be able to go home if treated, would you rather not have the treatment?

- What are your expectations about the goals of care for you/your child?

- What treatments do you want or do not want for yourself/your child?

Advance Care Plan Checklist:

$\square$ Patient name

$\square$ Date of birth

$\square$ Health record number (if applicable)

$\square$ Patient's age

$\square$ List of significant medical conditions

$\square$ A statement about the background to the advance care plan: (Patient's name)'s quality of life is paramount to all of those involved in his/her care. It is believed that he/she is at risk of future complications including respiratory or cardiac arrest, for which treatments including intensive care, ventilation, and blood pressure medications have been considered

$\square$ Directions for future care in the event of significant cardiorespiratory compromise:

\section{$\square$ A full DNR order}

In the event of a cardiac arrest, no resuscitative efforts will be attempted

\section{$\square$ A limited DNR order}

In the event of a cardiac arrest, the following limited resuscitative efforts may be attempted:

$\square$ Bag-mask ventilation

$\square$ Chest compressions

$\square$ Resuscitation medications (eg, adrenaline, atropine) $\square$ A list of life-sustaining treatments that will or will not be provided:

$\square$ Intubation and mechanical ventilation (breathing machine)

$\square$ Inotrope therapy (medications to support blood pressure)

$\square$ Dialysis (kidney machine)

$\square$ Artificial nutrition and/or hydration (may opt to discuss these treatments separately)

$\square$ Other treatments: eg, antibiotics, transfusions

(This next section may or may not be appropriate to include in the advance care plan depending on the child's health status, trajectory of illness, etc)

$\square$ A description of comfort measures (eg, oral fluids, opioid analgesia) that will be provided whether the plan is to continue, not start or discontinue potentially life-sustaining treatments. Consider adding plan of care for comfort measures including medication doses $(\mathrm{mg} / \mathrm{kg})(\mathrm{eg}$, in the event of breathlessness), if appropriate to the patient's condition

$\square$ A statement that the document is aimed to guide health care providers in providing care that is consistent with the hope and expectations for (patient's name)'s condition should he/she deteriorate. This plan represents the current consensus of the patient (if appropriate), parents/legal substitute decision-makers and the health care team. It is subject to alteration if the goals of treatment or other circumstances change, and should be reviewed periodically

$\square$ Name, position/role and signature of the health care practitioner drafting the advance care plan

$\square$ Health care practitioner contact information

$\square$ Date of the advance care plan

$\square$ Alternate contact information for parents or legal substitute decision-maker(s)

$\square$ Who is involved in the care of the child

$\square$ Copies to: (Patient's name) (if mature minor)

(Names of parents or legal substitute decision-maker[s])

School, Home Care nursing agency, etc

Health Records Department

Other physicians (family doctor, paediatric subspecialists)

\section{BIOETHICS COMMITTEE}

Members: Drs Susan Albersheim, BC Children's Hospital, Vancouver, British Columbia; Conrad Fernandez, IWK Health Centre, Halifax, Nova Scotia; Robert Hilliard, The Hospital for Sick Children, Toronto, Ontario; Pascale Gervais, Centre hospitalier de l'Université Laval, Sainte-Foy, Quebec (board representative), Ellen Tsai, Kingston General Hospital, Kingston, Ontario (chair)

Principal Author: Dr Ellen Tsai, Kingston General Hospital, Kingston, Ontario

The recommendations in this statement do not indicate an exclusive course of treatment or procedure to be followed. Variations, taking into account individual circumstances, may be appropriate.

All Canadian Paediatric Society position statements/notes are reviewed, revised or retired as needed on a regular basis.

Please consult the "Position Statements" section of the CPS website

(www.cps.ca/english/publications/statementsindex.htm) for the current version. 